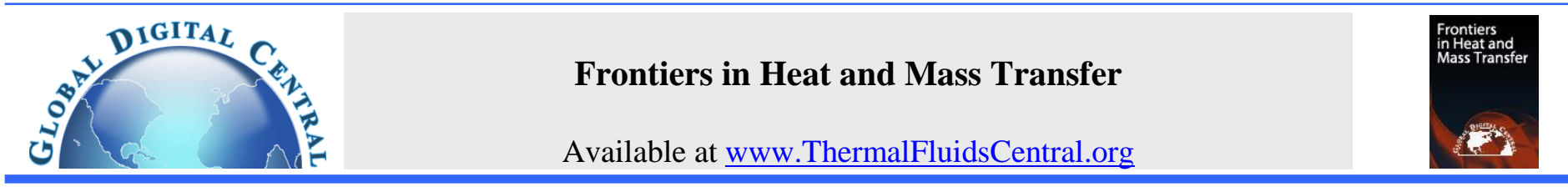

\title{
MHD MIXED CONVECTION FLOW OF A NON-NEWTONIAN POWELL- ERYING FLUID OVER A PERMEABLE EXPONENTIALLY SHRINKING SHEET
}

\author{
Astick Banerjee $^{\mathrm{a}}$, Aurang Zaib ${ }^{\mathrm{b}}$, Krishnendu Bhattacharyya ${ }^{\mathrm{c}, *}$, S.K. Mahato ${ }^{\mathrm{d}}$ \\ ${ }^{a}$ Mohulara Jr. High School, Birbhum-731236, West Bengal, India \\ ${ }^{b}$ Department of Mathematical Sciences, Federal Urdu University of Arts, Science \& Technology, Gulshan-e-Iqbal Karachi, Pakistan \\ ${ }^{c}$ Department of Mathematics, Institute of Science, Banaras Hindu University, Varanasi-221005, Uttar Pradesh, India \\ ${ }^{b}$ Department of Mathematics, Sidho Kanho Birsha University, Purulia-723104, West Bengal, India
}

\begin{abstract}
The magnetohydrodynamic (MHD) mixed convection heat transfer in a non-Newtonian Powell-Erying fluid flow due to an exponentially shrinking porous sheet is investigated. Both assisting and opposing flows are considered. After use of the suitable transformations, the governing equations become non-similar ODEs. Numerical computations of resulting equations are obtained by very efficient shooting method for several values of involved parameters. The results exhibit that dual non-similar solutions can be found only when some amount of fluid mass is sucked from the flow field through the porous sheet. Many important results on the effect of external magnetic field on mixed convective flow of Powell-Erying fluid have been explored. Where, it is found that dual non-similar solutions exist for the opposing flow, while for the assisting flow, solution is unique and for steady Powell-Erying fluid flow stronger mass suction is required compared to the Newtonian fluid flow.
\end{abstract}

Keywords: MHD flow; mixed convection; non-Newtonian Powell-Erying fluid; exponentially shrinking sheet; dual non-similar solutions.

\section{INTRODUCTION}

The magnetohydrodynamic (MHD) flow of fluid and heat transfer due to a stretching/shrinking sheet is occurred in many problems in geophysics and astrophysics and has several engineering applications such as in MHD generators, geothermal energy extractions, plasma studies, control of boundary layer in aerodynamics and many more. In particular, to control the behavior of the boundary layer, several methods are already developed and out of that, the application of MHD principle is very important method which can alter the structure of boundary layer to the desired direction. The MHD parameter is quite important in controlling the cooling rate and to achieve the best quality product (Hayat et al., 2012a). A comprehensive survey of MHD studies and their applications can be found in the book by Moreau (1990). The study of the MHD boundary layer flow of electrically conducting fluid in presence of a uniform magnetic field was considered by Ariel (1994). Later, Mahapatra and Gupta (2001) studied the MHD stagnation-point flow over a stretching sheet. The radiation effect on MHD flow and heat transfer towards a porous stretching surface was examined by Mukhopadhyay et al. (2010). Ali et al. (2011) investigated the steady MHD mixed convection stagnation-point flow of a electrically conducting fluid over a vertical flat plate. Mukhopadhyay (2013) investigated MHD boundary layer flow with heat transfer effects over a permeable exponential stretching sheet. Tamim et al. (2014) studied the MHD mixed convective stagnation point flow of a nanofluid over a vertical permeable plate.

In the above discussions, Newtonian fluid flows are discussed. But in modern engineering, many fluids show non-Newtonian behavior, therefore many researchers are more interested in those industrial non-
Newtonian fluids and their dynamics. A single constitutive equation is not sufficient to describe all physical properties of non-Newtonian fluids and thus several non-Newtonian fluid models (Wilkinson, 1970; Rajagopal, 1980; Rajagopal et al., 1984; Dorier and Tichy, 1992) have been introduced to explain all such behaviors. The one of such nonNewtonian fluid is Powell-Eyring fluid. The Powell-Eyring fluid model has a clear advantage over all the other non-Newtonian fluids because it is derived from kinetic theory of gases rather than from the empirical relations. Moreover, its behavior is like a viscous fluid when shear rates are high (Roşca and Pop, 2014a). The boundary layer flow of a Powell-Eyring fluid past a moving surface with convective boundary condition was discussed by Hayat et al. (2012b). Jalil et al. (2013) studied the flow of Powell-Eyring fluid and heat transfer over a continuously moving permeable surface in the presence of a parallel free stream. Panigrahi et al. (2014) investigated the mixed convective flow of Powell-Eyring fluid past a nonlinear permeable stretching surface with magnetic field. Recently, Akbar et al. (2015) investigated MHD boundary layer flow of a Powell-Eyring fluid past a stretching surface.

Recently, the boundary layer flow developed over a shrinking sheet has attracted the considerable attention of many researchers similar to that of stretching sheet for its increasing technological applications. The flow due to the shrinking sheet is more physically interesting than that of the stretching sheet flow. The existence and uniqueness of the similarity solution for the flow past a shrinking surface were investigated by Miklavčič and Wang (2006). The flow patterns of various Newtonian and non-Newtonian fluids on a shrinking sheet are discussed by many researchers (Hayat et al., 2008; Fang and Zhang, 2009; Lok et al., 2011; Bhattacharyya et al., 2012). On the other

\footnotetext{
*Corresponding author.Email: krish.math@yahoo.com,krishmath@bhu.ac.in
} 
hand, very limited attention has been given to study the flow over an exponentially stretching/shrinking sheet though it is very significant in numerous engineering problems. First, Magyari and Keller (1999) investigated the boundary layer flow and heat transfer due to exponentially stretching sheet. The flow and heat transfer over an exponentially stretching sheet with wall mass suction was examined by Elbashbeshy (2001). Al-Odat et al. (2006) investigated the MHD effect on the thermal boundary layer over an exponentially stretching surface with temperature distribution being in exponential form. Later, Sajid and Hayat (2008) examined the effect of thermal radiation on the boundary layer flow over exponentially stretching sheet and reported series solutions by homotopy analysis method (HAM) for velocity and temperature. Ishak (2011) investigated numerically the radiation effect on flow and heat transfer past exponentially stretching surface. On the other hand, the flow due to exponential shrinking sheet with heat transfer was analysed by Bhattacharyya (2011) and the effect of external magnetic field on this flow was illustrated by Bhattacharyya and Pop (2011). Boundary layer flow over an exponentially shrinking sheet near a stagnation-point was discussed by Bhattacharyya and Vajravelu (2012) and same problem with nanoparticle effect was studied by Bachok et al. (2012). Ara et al. (2014) investigated the heat transfer in boundary layer flow of an Eyring-Powell fluid in presence of thermal radiation. Ghosh and Mukhopadhyay (2017) demonstrated the steady nanofluid flow past an exponentially permeable shrinking sheet in presence of slip.

In this paper, the properties of MHD mixed convective boundary layer flow and heat transfer of non-Newtonian Powell-Eyring fluid due to a permeable exponentially shrinking sheet are discussed. The effects of external magnetic field, mixed convection parameter, suction and fluid parameters on the skin friction coefficient and the local Nusselt number along with the velocity and temperature profiles are analyzed and discussed. In best of our knowledge, the investigation of this mixed convection flow is not reported so far.

\section{MATHEMATICAL FORMULATION}

Let us consider an incompressible steady 2D flow of non-Newtonian Powell-Eyring fluid past a permeable exponentially shrinking sheet. The shrinking velocity and surface temperature are in exponential mode. The velocity of the shrinking sheet is $u_{w}=a e^{x / L}$ with $a$ being shrinking constant, the variable surface temperature is $T_{w}=T_{\infty}+b e^{2 x / L}$ and constant temperature away from the sheet is $T_{\infty}$, where $T_{w}>T_{\infty}$ corresponds to heated surface (assisting flow) and $T_{w}<T_{\infty}$ corresponds to cooled surface (opposing flow), respectively. A variable magnetic field $B(x)=B_{0} e^{x / 2 L}$ ( $B_{0}$ being constant) is taken and is applied normal to the sheet. The magnetic Reynolds number for the flow is considered to be very small, so that the induced magnetic field can be neglected. The constitutive equations for Eyring-Powell fluid model is given below (Hayat et al., 2012b):

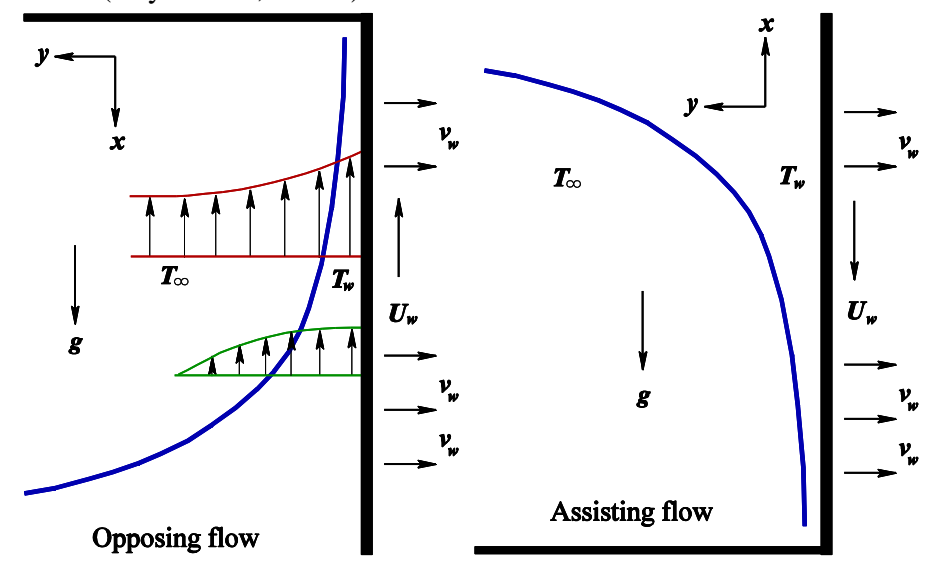

Fig. 1 Physical sketch of the problem.
$\bar{S}=\mu \nabla \bar{V}+\frac{1}{\beta_{1}} \sinh ^{-1}\left(\frac{1}{c} \nabla \bar{V}\right)$

and

$\sinh ^{-1}\left(\frac{1}{c} \nabla \bar{V}\right) \approx \frac{1}{c} \nabla \bar{V}-\frac{1}{6}\left(\frac{1}{c} \nabla \bar{V}\right)^{3},\left|\frac{1}{c} \nabla \bar{V}\right|<<1$,

where $\mu$ is the viscosity, $\beta_{1}$ and $c$ are the material fluid parameters.

Under these conditions boundary layer equations for steady flow of Eyring-Powell fluid and heat transfer over a permeable exponentially shrinking surface may be written in usual notation as:

$\frac{\partial u}{\partial x}+\frac{\partial v}{\partial y}=0$

$u \frac{\partial u}{\partial x}+v \frac{\partial u}{\partial y}=\left(v+\frac{1}{\rho \beta_{1} c}\right) \frac{\partial^{2} u}{\partial y^{2}}-\frac{1}{2 \rho \beta_{1} c^{3}}\left(\frac{\partial u}{\partial y}\right)^{2} \frac{\partial^{2} u}{\partial y^{2}}$ $-\frac{\sigma B^{2}(x)}{\rho} u+g \beta_{T}\left(T-T_{\infty}\right)$,

$u \frac{\partial T}{\partial x}+v \frac{\partial T}{\partial y}=\frac{\kappa}{\rho c_{p}} \frac{\partial^{2} T}{\partial y^{2}}$.

The corresponding boundary conditions are

$u=-u_{w}(x), v=-v_{w}, T=T_{w}(x)$ at $y=0$

$u \rightarrow 0, T \rightarrow T_{\infty}$, as $y \rightarrow \infty$,

where $u$ and $v$ are the velocity components in $x$ and $y$ directions respectively, $a$ is a positive constant, $v$ is the kinematic fluid viscosity, $\rho$ is the density, $v_{w}=v_{0} e^{x / 2 L}$ is the variable suction velocity with $v_{0}$ being constant, $T$ is the temperature, $\beta_{T}$ is the thermal expansion coefficient, $g$ is the gravitational acceleration, $L$ is the reference length, $\kappa$ is the thermal diffusivity and $c_{p}$ is the specific heat. The physical sketch of the problem is given in Fig. 1.

Let us introduce the following transformation:

$\left.\begin{array}{l}u=a e^{x / L} f^{\prime}(\eta), v=-\sqrt{\frac{a v}{2 L}} e^{x / 2 L}\left[f(\eta)+\eta f^{\prime}(\eta)\right], \\ \eta=\sqrt{\frac{a}{2 L v}} e^{x / 2 L} y, T=T_{\infty}+b e^{2 x / L} \theta(\eta) .\end{array}\right\}$

Using (8), the continuity equation (3) is automatically satisfied and the nonlinear partial differential equations (4) and (5) are converted into the following non-similar ordinary differential equations:

$(1+\varepsilon) f^{\prime \prime \prime}+f f^{\prime \prime}-2 f^{\prime 2}-\varepsilon \delta f^{\prime \prime 2} f^{\prime \prime \prime}-2 M f^{\prime}+2 \lambda \theta=0$,

$\frac{1}{\operatorname{Pr}} \theta^{\prime \prime}+f \theta^{\prime}-4 f^{\prime} \theta=0$

and the boundary conditions (6) and (7) become

$f(0)=S, f^{\prime}(0)=-1, \theta(0)=1$

$f^{\prime}(\infty) \rightarrow 0, \theta(\infty) \rightarrow 0$,

where prime denotes differentiation with respect to $\eta, \varepsilon=1 /\left(v \rho \beta_{1} c\right)$ and $\delta=a^{3} e^{3 x / L} /\left(4 v L c^{2}\right)$ are the local fluid parameters, $\operatorname{Pr}=\mu c_{p} / \kappa$ is the Prandtl number, $\lambda=g \beta_{T} b L / a^{2}$ is the mixed convection parameter, $M=\sigma B_{0}^{2} L /(a \rho)$ is the magnetic parameter and $S=v_{0} \sqrt{2 L /(a v)}>0$ is the mass suction parameter.

The physical quantities of significance interest are local skin friction coefficient and local Nusselt number which are defined as:

$C_{f}=\frac{\left.\tau_{w}\right|_{y=0}}{\rho u_{w}^{2}}, N u_{x}=\frac{\left.x q_{w}\right|_{y=0}}{\kappa\left(T_{w}-T_{\infty}\right)}$,

where $\tau_{w}$ is shear stress along the exponentially shrinking sheet and $q_{w}$ is heat flux from the sheet and those are defined as 


$$
\tau_{w}=\left(\mu+\frac{1}{\beta_{1} c}\right)\left(\frac{\partial u}{\partial y}\right)-\frac{1}{6 \beta_{1} c^{3}}\left(\frac{\partial u}{\partial y}\right)^{3}, q_{w}=-\kappa\left(\frac{\partial T}{\partial y}\right) .
$$

Therefore, the wall skin friction coefficient $C_{f}$ and local Nusselt number $N u_{x}$ are found as follows:

$$
\begin{aligned}
& C_{f} \operatorname{Re}_{x}^{1 / 2} \sqrt{\frac{2 L}{x}}=(1+\varepsilon) f^{\prime \prime}(0)-\frac{1}{3} \varepsilon \delta f^{\prime \prime 3}(0), \\
& N u_{x} \operatorname{Re}_{x}^{-1 / 2} \sqrt{\frac{2 L}{x}}=-\theta^{\prime}(0),
\end{aligned}
$$

where $\operatorname{Re}_{x}=x u_{w} / v$ is local Reynolds number.

\section{RESULTS AND DISCUSSION}

The transformed equations (9) \& (10) with boundary conditions (11) are solved numerically using shooting method and the detail description of the scheme can be found in the article by Bhattacharyya (2013). The study of the obtained numerical results explores the condition for which steady flow of the non-Newtonian Powell-Eyring fluid is possible. According to study of Miklavčič and Wang (2006) and Fang and Zhang (2009), for Newtonian fluids, the steady two-dimensional flow due to a shrinking surface with wall mass transfer through the porous sheet is possible when the wall mass suction parameter is larger than or equal to 2. However, it is quite different for non-Newtonian Powell-Eyring fluid. With increasing values of $\varepsilon$, for the steady flow larger amount of mass suction is required in comparison with the Newtonian fluid flow. For $\varepsilon=0.1$, the flow has dual non-similar solution for $S \geq 2.4470$ and consequently for $S<2.4470$ no non-similar solution is possible. For $\varepsilon=0.2$, the dual non-similar solutions exist for ranges of $S$ is $S \geq 2.5289$ and therefore no non-similar solution is found for $S<2.5289$. Further, it is interesting to note that more increment in fluid parameter $\varepsilon$ causes more reduction in the range of suction parameter for which solution exists. For $\varepsilon=0.3$, the ranges of $S$ where dual non-similar solutions exist, is $S \geq 2.60735$ and no solution exists for $S<2.60735$. The variation of skin friction coefficient and local Nusselt number for selected values of the fluid parameter $\varepsilon$ are depicted in Figs. 2 and 3, respectively. In these figures, the solid lines denote first solution (the upper branch solution), while the dash lines denote second solution (the lower branch solution). From Figs. 2 and 3, it is noticed that for the first solution the values of skin friction coefficient and local Nusselt number decrease with increasing values of $\varepsilon$ and the values increase for second solution.

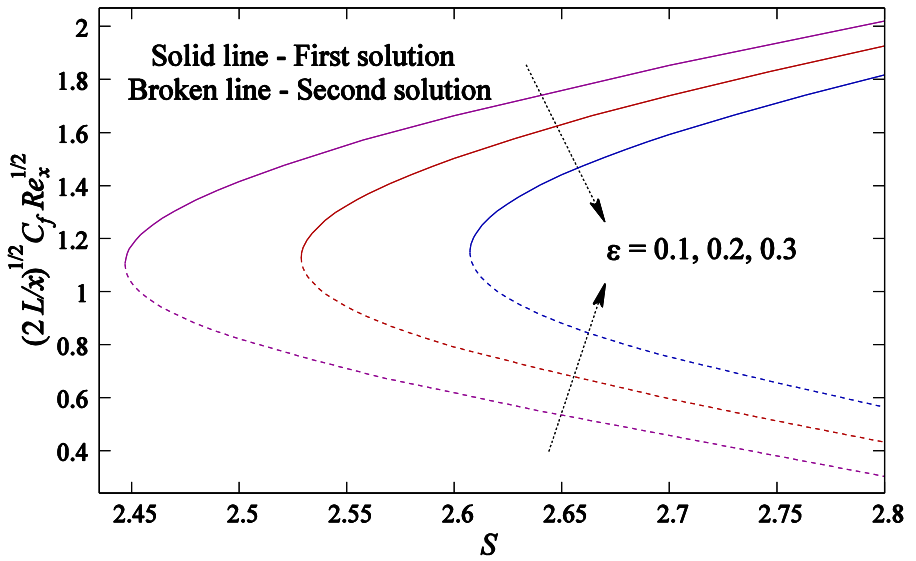

Fig. 2 The Skin friction coefficient vs. $S$ for different values of $\varepsilon$ with $\delta=0.1, \lambda=-0.1, M=0.1, \operatorname{Pr}=1$.

The skin friction coefficient and local Nusselt number for different values of $S$ are presented in Figs. 4 and 5, respectively. It can be observed that dual solutions exist for opposing flow $(\lambda<0)$, while for the assisting flow $(\lambda>0)$, the solution is unique. For the first solution, the values of skin friction coefficient and local Nusselt number increase as $\lambda$ increases. This is due to the fact that the assisting buoyancy forces produce a favorable pressure gradient which increases the fluid motion. On the other hand, for first solution, skin friction coefficient and the local Nusselt number decrease as $S$ increases, while for the second solution, those values increase. It is evident from these figs that mass suction delays the boundary layer separation. It is also worth mentioning that the computations have been performed until we get the solution with desired accuracy level in asymptotic nature with the boundary conditions and the computations were terminated at this point. For different values of $S$, there are critical values $\lambda_{c}(<0)$ of $\lambda$ from which the solution exists. Based on the computations, the critical values are $-0.37450,-0.25199$ and -0.15480 for $S=2.6,2.7$ and 2.8 , respectively.

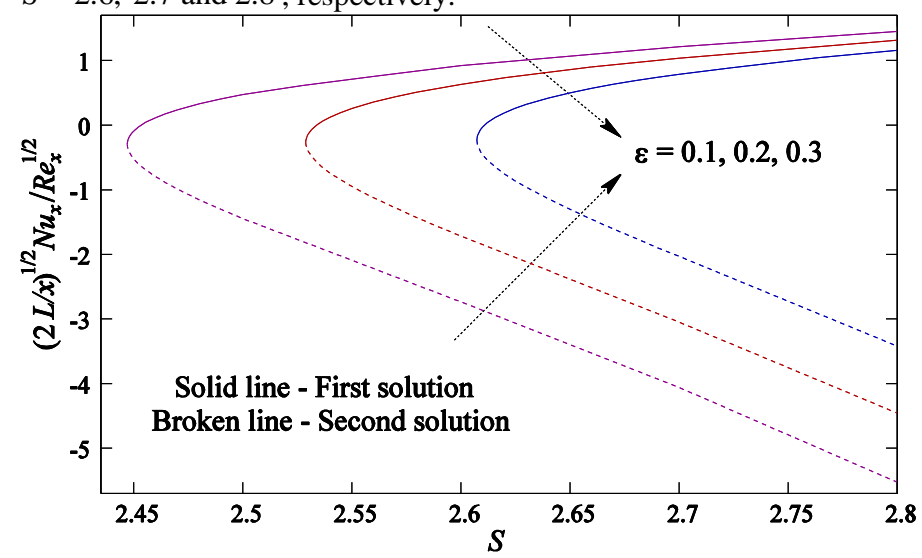

Fig. 3 The local Nusselt number vs. $S$ for different values of $\varepsilon$ with $\delta=0.1, \lambda=-0.1, M=0.1, \operatorname{Pr}=1$.

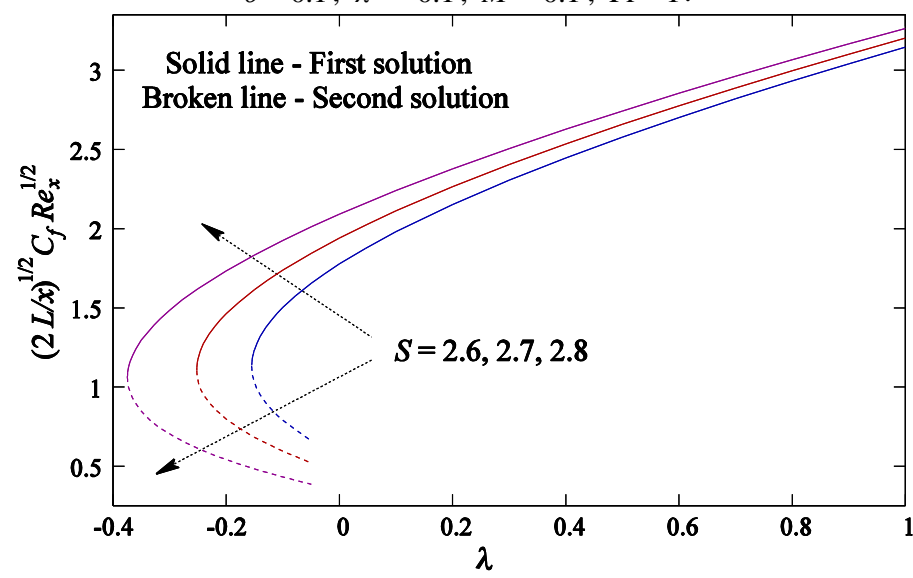

Fig. 4 The Skin friction coefficient vs. $\lambda$ for different values of $S$ with

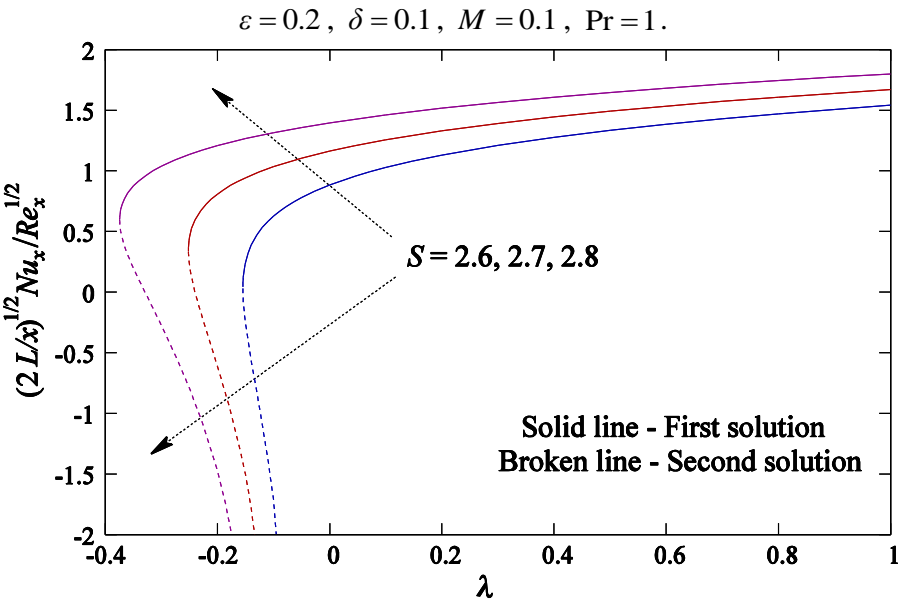

Fig. 5 The local Nusselt number vs. $\lambda$ for different values of $S$ with $\varepsilon=0.2, \delta=0.1, M=0.1, \operatorname{Pr}=1$.

Figs. 6 and 7 show the variation of skin friction coefficient and local Nusselt number for several values of $M$. From Figs. 6 and 7, it is observed that the values of skin friction and local Nusselt number increase with $M$ for first solution, while the values decrease for second solution. It is also seen from Fig. 6 that the wall shear stress is positive 
which implies that the fluid exert a drag force on the sheet. It is worth mentioning that the first solution is stable and physically relevant, while the second solution is not, since the first solution is the only solution for the case of assisting flow, and the second solution exists only for certain range of few parameters. However, they are still of interest as the differential equations are concerned, though such solutions are deprived of physical significant. Similar results may arise in other physical situations where the corresponding solutions could have more real meaning (Ridha, 1996). For the similar problems, using a stability analysis, Weidman et al. (2006), Postelnicu and Pop (2011) and very recently by Roşca and Pop (2014b) have shown that first solutions are stable, while second solutions are not.

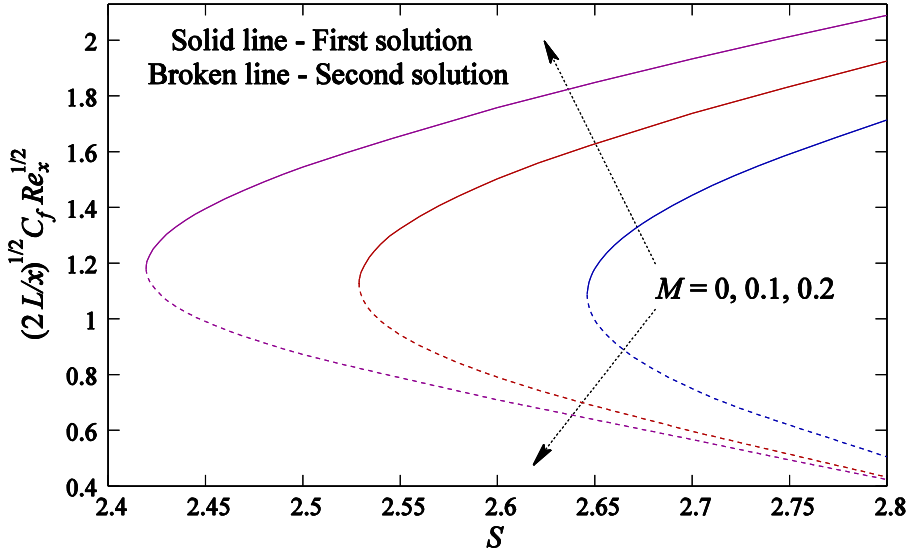

Fig. 6 The Skin friction coefficient vs. $S$ for different values of $M$. with

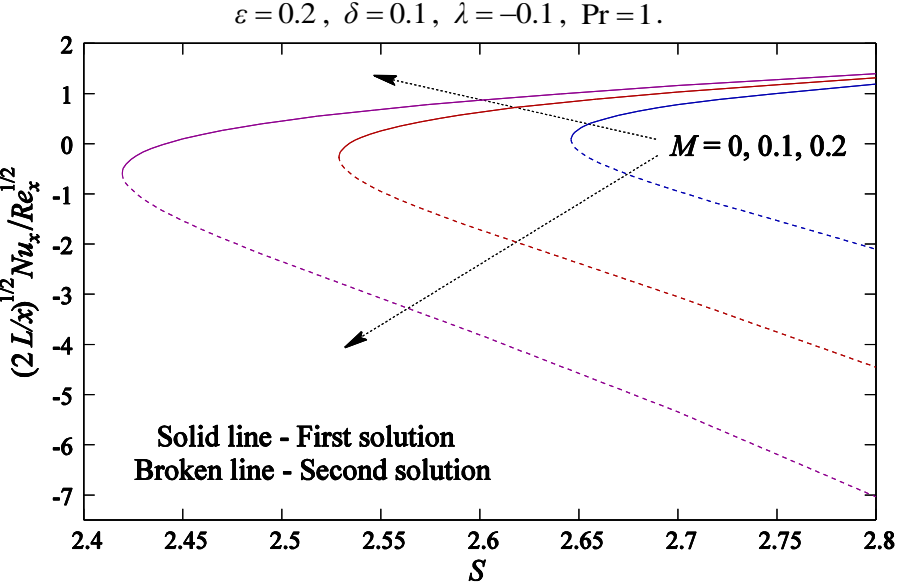

Fig. 7 The local Nusselt number vs. $S$ for different values of $M$ with

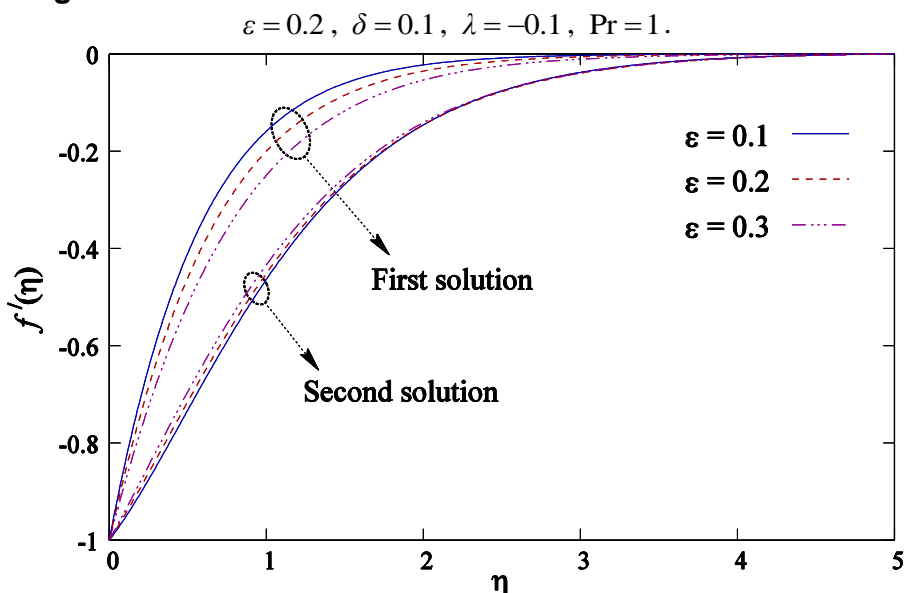

Fig. 8 The velocity profiles for different values of $\varepsilon$ with $\delta=0.1$,

$$
M=0.1, S=2.7, \lambda=-0.1, \operatorname{Pr}=1 .
$$

The velocity and temperature profiles for different values of fluid parameters $\varepsilon$ and $\delta$ are depicted in Figs. 8-11. Fig. 8 shows that velocity profiles decreases with increasing $\varepsilon$ and consequently it increases the velocity boundary layer thickness for first solution, while the opposite trend is observed for second solution. On the other hand, the opposite way is noted for the fluid parameter $\delta$ as shown in Fig. 10. It is also clear from these figures that the second solution displays a thicker boundary layer thickness compared to first solution. Fig. 9 shows that both the temperature and thermal boundary layer thickness increase with $\varepsilon$ for first solution and decrease for second solution. Fig. 11 shows temperature profiles decreases with increasing $\delta$ for first solution and increases for second solution. It is worth mentioning that first and second solutions satisfied the far field boundary conditions asymptotically, which is supporting the accuracy of obtained numerical results.

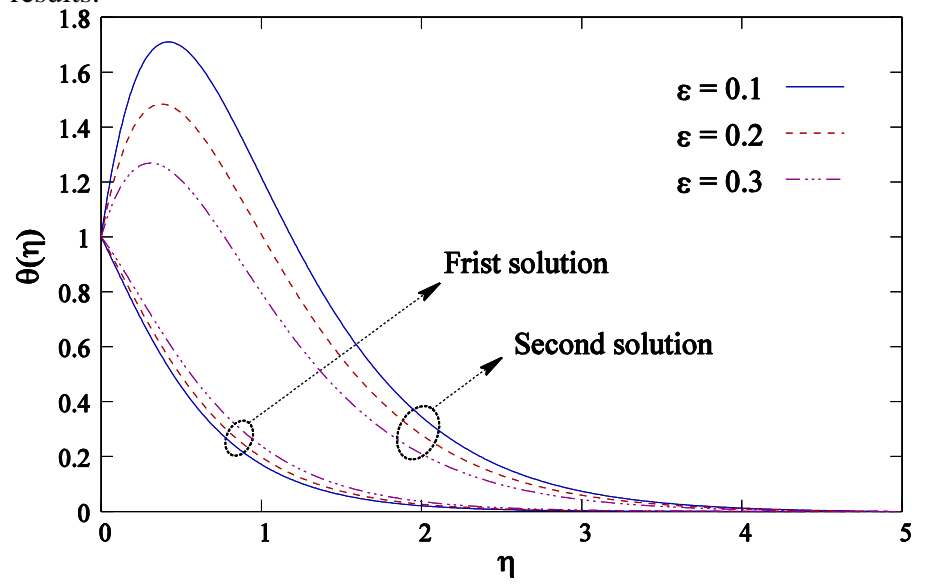

Fig. 9 The temperature profiles for different values of $\varepsilon$ with $\delta=0.1$,

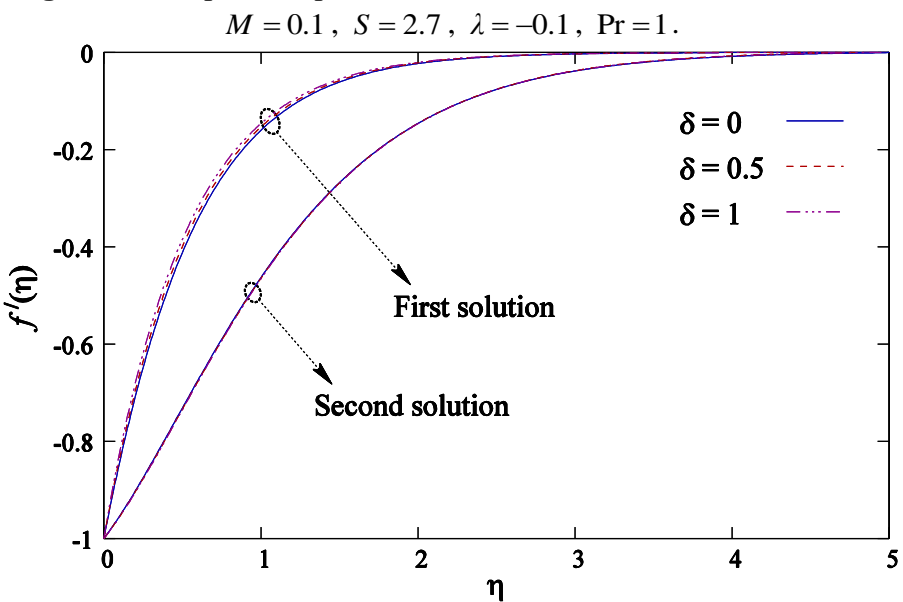

Fig. 10 The velocity profiles for different values of $\delta$ with $\varepsilon=0.1$, $M=0.1, S=2.7, \lambda=-0.1, \operatorname{Pr}=1$.

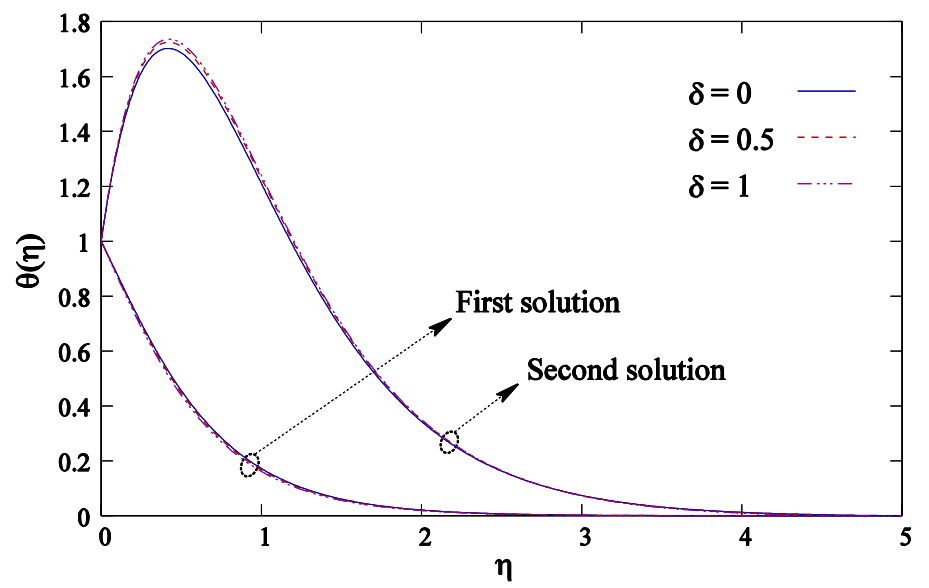

Fig. 11 The temperature profiles for different values of $\delta$ with $\varepsilon=0.1$, $M=0.1, S=2.7, \lambda=-0.1, \operatorname{Pr}=1$. 
The suction plays an important role to maintain the steady flow near the surface by delaying the flow separation. So, the effects of suction parameter $S$ on the velocity and temperature profiles are vital in theoretical and practical points of view. Figs. 12 and 13 illustrated the velocity and temperature profiles for various values of suction $S$. Fig. 12 shows that, for first solution, velocity profiles increases with increasing $S$ and it decreases for second solution. From Fig. 13, it is clear that thermal boundary layer thickness decreases with increasing $S$ for first solution and increases for second solution. Due to suction the fluid mass is brought closer to the sheet and by this it prevents the diffusion of vorticity generated due to shrinking.

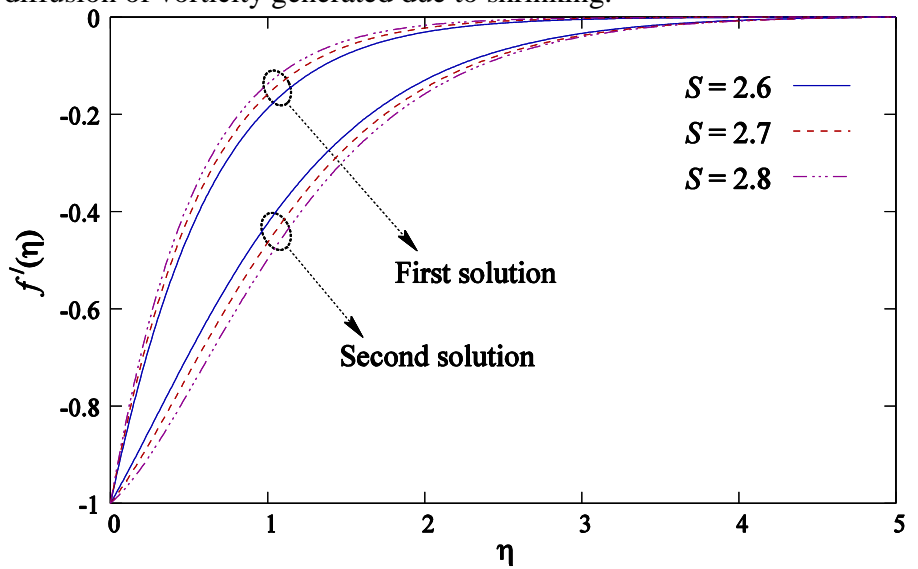

Fig. 12 The velocity profiles for different values of $S$ with $\varepsilon=0.1$, $\delta=0.1, M=0.1, \lambda=-0.1, \operatorname{Pr}=1$.

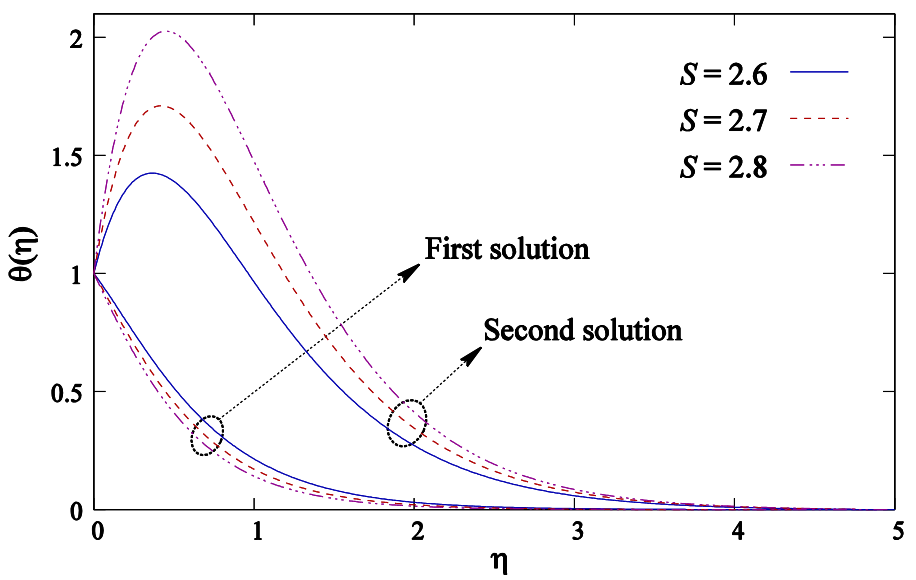

Fig. 13 The temperature profiles for different values of $S$ with $\varepsilon=0.1$, $\delta=0.1, M=0.1, \lambda=-0.1, \operatorname{Pr}=1$.

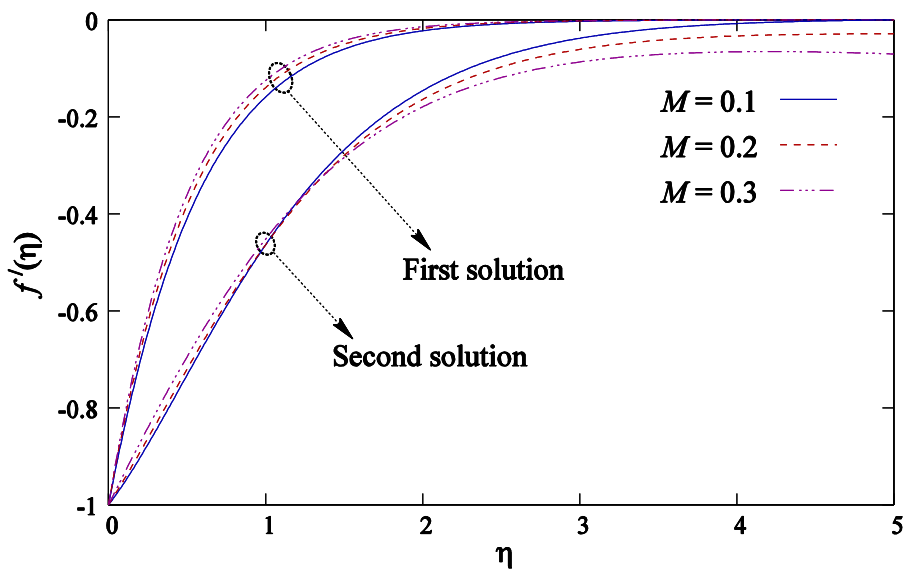

Fig. 14 The velocity profiles for different values of $M$ with $\varepsilon=0.1$, $\delta=0.1, S=2.7, \lambda=-0.1, \operatorname{Pr}=1$.
Figs. 14 and 15 show the effect of magnetic parameter on velocity and temperature profiles. From Fig. 14, it is clear that the velocity of fluid increases and consequently there is reduction in the velocity boundary layer thickness for first solution, whereas the opposite effects are observed in case of second solution. With a rise in strength of magnetic field (i.e., increase of magnetic parameter), the Lorentz force associated with applied magnetic field makes the boundary layer thinner due to its resistance property. The fluid which is decelerated by the viscous action, receives a push due to the magnetic field which works against the viscous effects (Mukhopadhyay and Mandal, 2015). For first solution, the thermal boundary layer thickness reduces with increasing $M$ and increases for second solution as found in Fig. 15. It is also noted that temperature profiles overshoot in the boundary layer region for second solution.

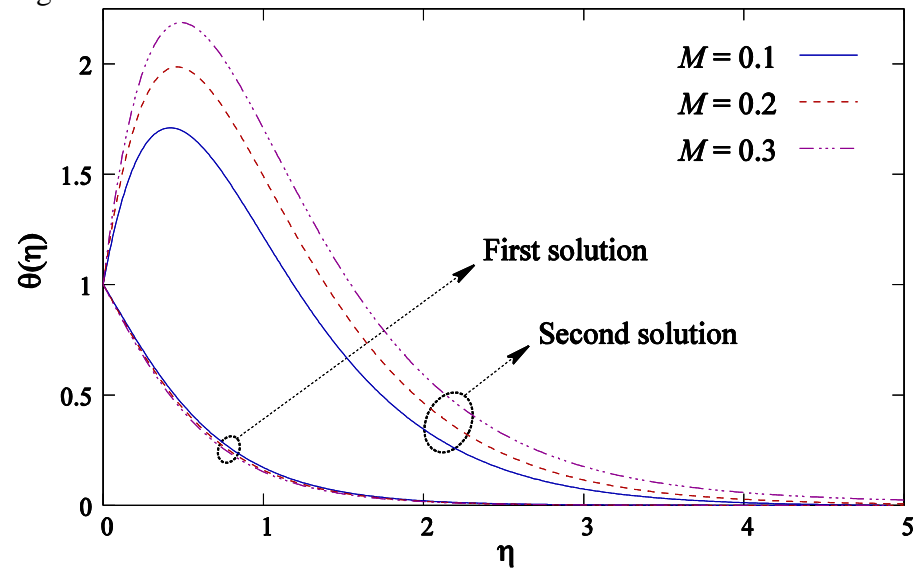

Fig. 15 The temperature profiles for different values of $M$ with $\varepsilon=0.1$,

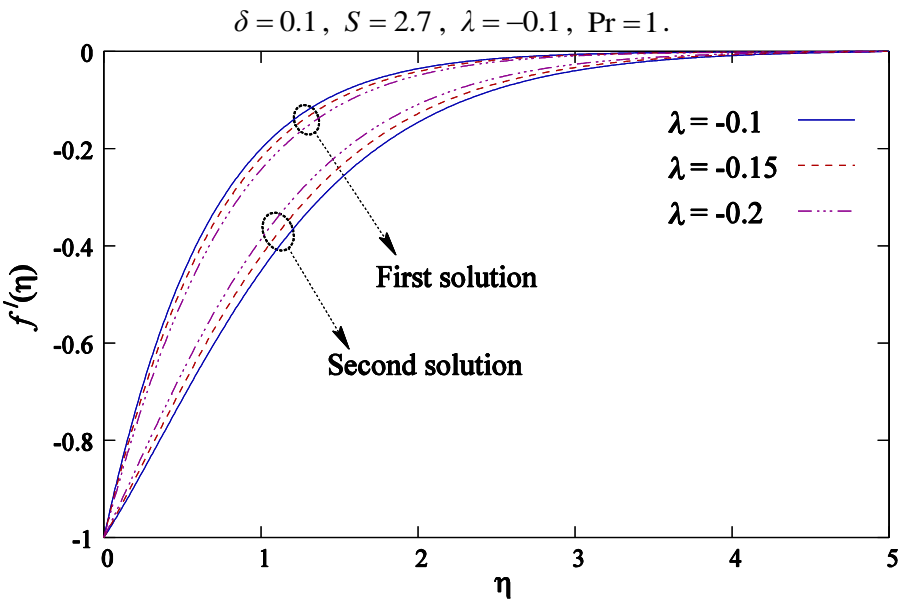

Fig. 16 The velocity profiles for different values of $\lambda(<0)$ with $\varepsilon=0.2$,

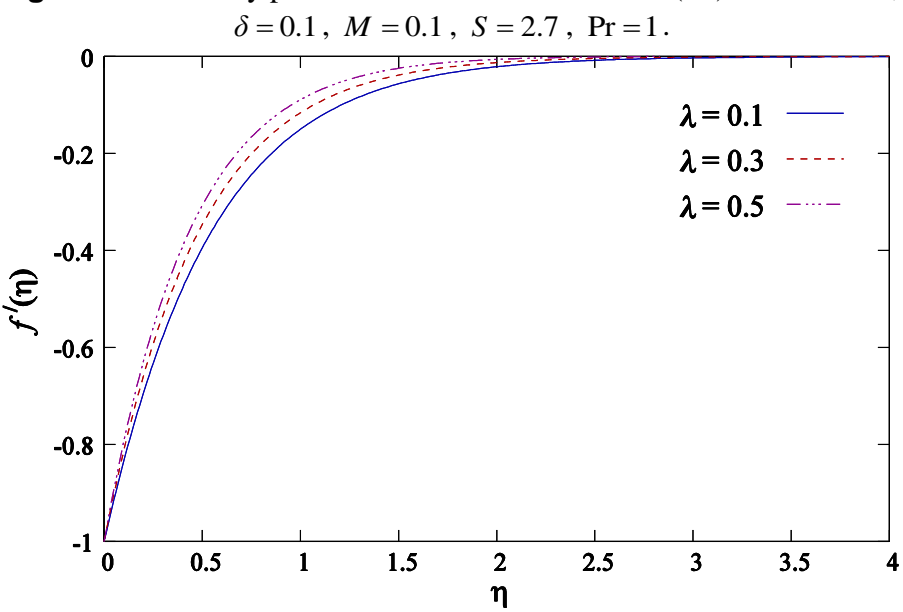

Fig. 17 The velocity profiles for different values of $\lambda(>0)$ with $\varepsilon=0.2$, $\delta=0.1, M=0.1, S=2.7, \operatorname{Pr}=1$. 
The effects of mixed convection parameter $\lambda$ on the dimensionless velocity and temperature profiles are depicted in Fig. $16-$ Fig. 19. For opposing flow $(\lambda<0)$, the velocity inside the boundary layer decreases with magnitude of $\lambda$ for first solution and reverse for second solution. Whereas, for assisting flow $(\lambda>0)$, the velocity increases with $\lambda$. As the magnitude of $\lambda$ (with $\lambda<0$ ) increases the influence of opposing buoyancy force become more prominent and it causes reduction of velocity. On the other hand, for $\lambda>0$, the opposing buoyancy force originates increment in the velocity. The effects of buoyancy forces on the temperature are just opposite to those of on the velocity. For $\lambda<0$ the temperature enhances with increasing magnitude of $\lambda$ for first solution and it reduces for second solution. For assisting flow, temperature decreases with $\lambda$.

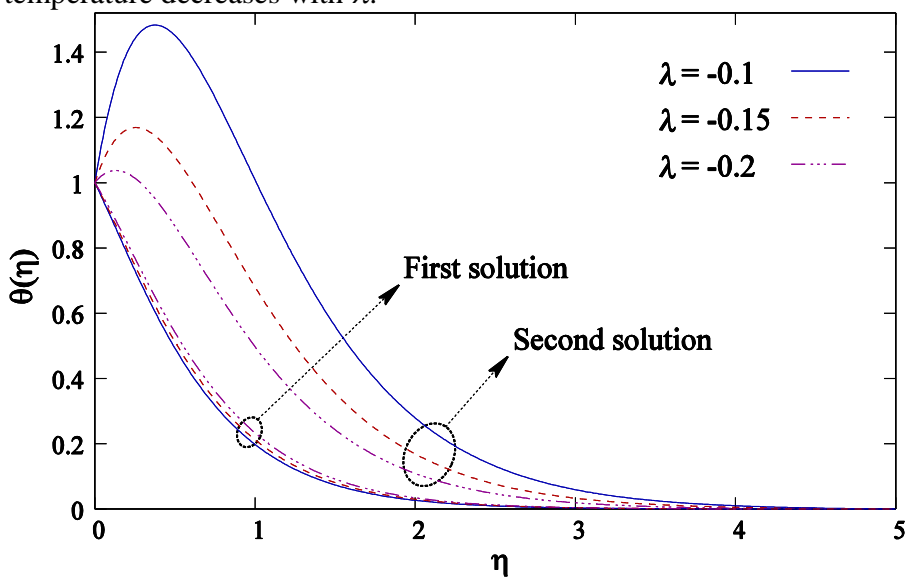

Fig. 18 The temperature profiles for different values of $\lambda(<0)$ with

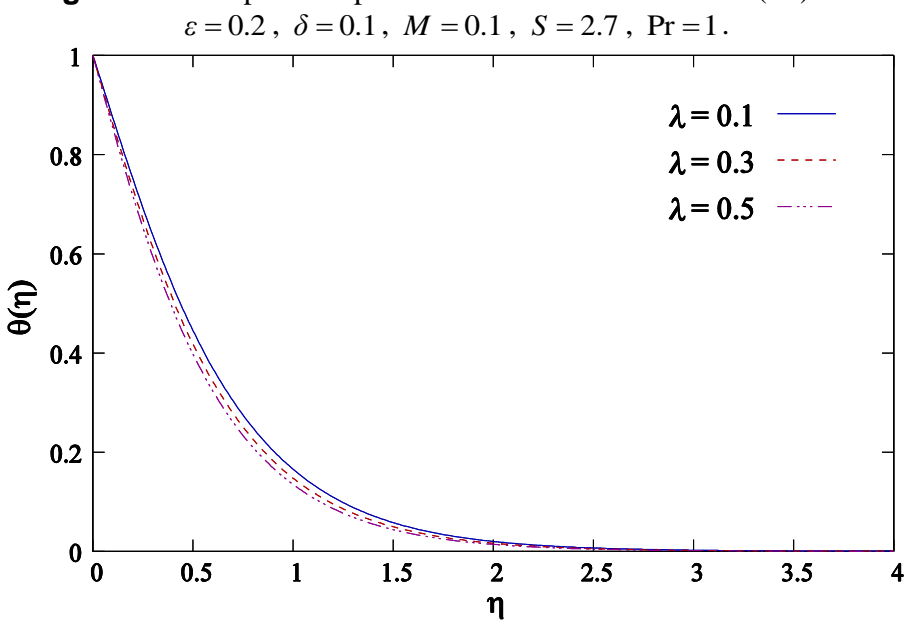

Fig. 19 The temperature profiles for different values of $\lambda(>0)$ with $\varepsilon=0.2, \delta=0.1, M=0.1, S=2.7, \operatorname{Pr}=1$.

A comparison of dual velocity profiles of the present study for $M=0.1, S=2.5, \varepsilon=0, \delta=0, \lambda=0$ with the published results by Bhattacharyya and Pop (2011) for $M=0.2, S=2.5$ ( $2 M=M$ is the relation between the two magnetic parameters of the two papers) is presented in Fig. 20. Those two are found in excellent agreement and it consequently confirms the accuracy of the obtained results.

\section{CONCLUSIONS}

A numerical study has been presented on MHD mixed convective flow and heat transfer of Powell-Eyring fluid past a permeable exponentially shrinking sheet. Non-similar dual solutions of the transformed equations are found using the shooting method for various values of governing parameters. Assisting as well as opposing flows are considered. The study can be summarized as follows:

(1) Dual solutions are obtained for a certain range of suction parameter and mixed convection parameter (only for opposing flow).
(2) For the increment of fluid parameter $\varepsilon$ and suction, skin friction coefficient enhances for first solution and reduces for second solution, whereas the skin friction increases due to magnetic parameter for first solution and decrease for second solution.

(3) The local Nusselt number decreases due to the suction and fluid parameter for fist solution and increases in case of second solution, while the Nusselt number increases with magnetic parameter.

(4) Both the boundary layer thicknesses decrease due to the fluid parameter $\delta$ in case of first solution, while those increase for second solution.
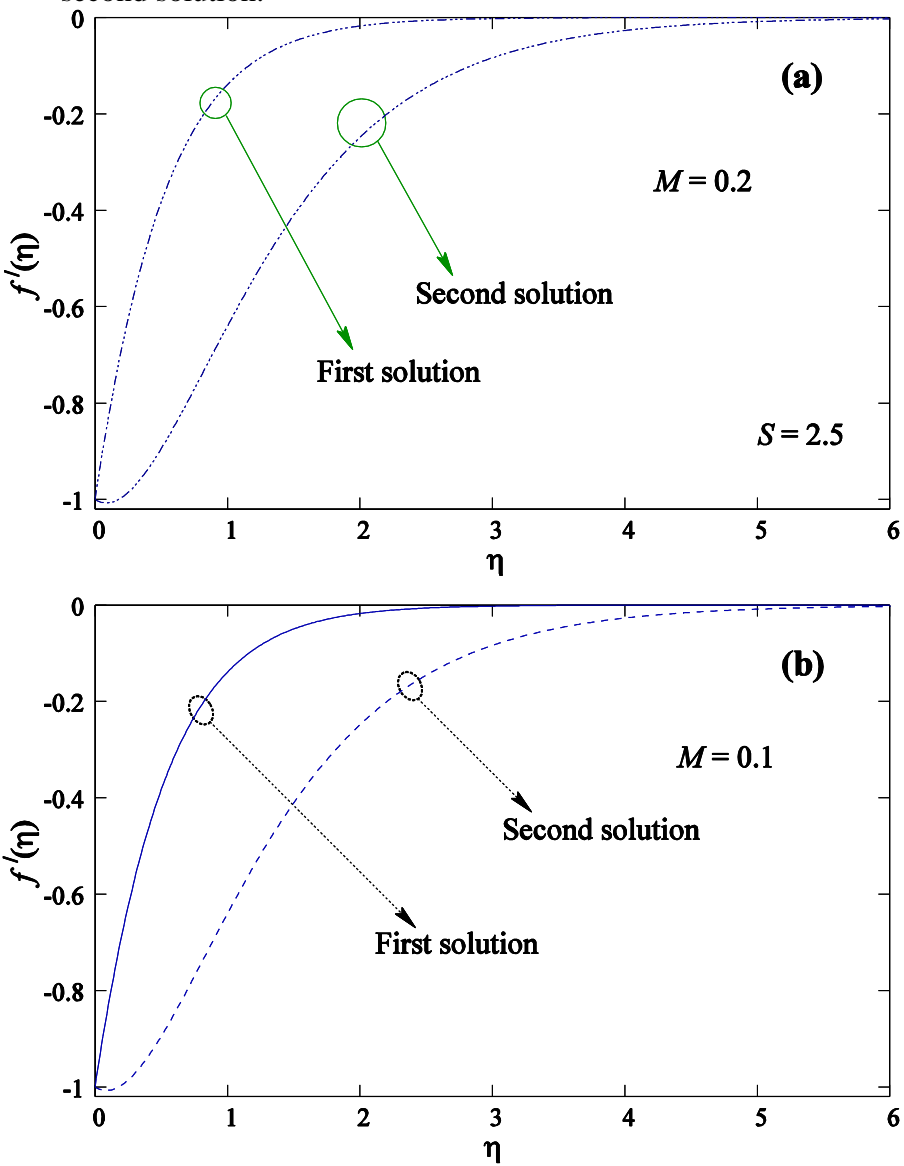

Fig. 20 A comparison of velocity profiles: (a) dual velocity profiles for $M=0.2, S=2.5$ by Bhattacharyya and Pop (2011) (b) dual velocity profiles for $\varepsilon=0, \delta=0, \lambda=0, M=0.1, S=2.5$ of present study.

\section{ACKNOWLEDGEMENTS}

The work of K. Bhattacharyya is supported by "UGC-BSR Research Start-Up-Grant". The authors want to express their sincere thanks to the reviewers for their valuable comments and suggestions.

\section{REFERENCES}

Akbar, N.S., Ebaid, A., and Khan, Z.H., 2015, "Numerical Analysis of Magnetic Field on Eyring-Powell Fluid Flow towards a Stretching Sheet," Journal of Magnetism and Magnetic Materials, 382, 355-358. https://doi.org/10.1016/j.jmmm.2015.02.002

Ali, F.M., Nazar, R., Arifin, N.M., and Pop, I., 2011, "MHD Mixed Convection Boundary Layer Flow toward a Stagnation-Point on a Vertical Surface with Induced Magnetic Field," Journal of Heat Transfer, 133(2), 1-6.

Al-Odat, M.Q., Damseh, R.A., and Al-Azab, T.A., 2006, "Thermal Boundary Layer on an Exponentially Stretching Continuous Surface in the Presence of Magnetic Field Effect," International Journal of Applied Mechanics and Engineering, 11(2), 289-299. 
Ara, A., Khan, N.A., Khan, H., and Sultan, F., 2014, "Radiation Effect on Boundary Layer Flow of an Eyring-Powell Fluid over an Exponentially Shrinking Sheet," Ain Shams Engineering Journal, 5(4), 1337-1342.

https://doi.org/10.1016/j.asej.2014.06.002

Ariel, P.D., 1994, "Hiemenz Flow in Hydromagnetics," Acta Mechanica 103(1-4), 31-43.

https://link.springer.com/article/10.1007/BF01180216

Bachok, N., Ishak, A., and Pop, I., 2012, "Boundary Layer StagnationPoint Flow and Heat Transfer over an Exponentially Stretching/Shrinking Sheet in a Nanofluid," International Journal of Heat and Mass Transfer, 55(25-26), 8122-8128.

https://doi.org/10.1016/j.ijheatmasstransfer.2012.08.051

Bhattacharyya, K., 2011, "Boundary Layer Flow and Heat Transfer over an Exponentially Shrinking Sheet," Chinese Physics Letters, 28(7), 074701.

Bhattacharyya, K., and Pop, I., 2011, "MHD Boundary Layer Flow Due to an Exponentially Shrinking Sheet," Magnetohydrodynamics, 47(4), 337-344.

Bhattacharyya, K., and Vajravelu, K., 2012, "Stagnation-Point Flow and Heat Transfer over an Exponentially Shrinking Sheet," Communications in Nonlinear Science and Numerical Simulation, 17(7), 2728-2734.

https://doi.org/10.1016/j.cnsns.2011.11.011

Bhattacharyya, K., Mukhopadhyay, S., Layek, G.C., and Pop, I., 2012, "Effects of Thermal Radiation on Micropolar Fluid Flow and Heat Transfer over a Porous Shrinking Sheet," International Journal of Heat and Mass Transfer, 55(11-12), 2945-2952.

https://doi.org/10.1016/j.ijheatmasstransfer.2012.01.051

Bhattacharyya, K., 2013, "Heat Transfer in Unsteady Boundary Layer Stagnation-Point Flow towards a Shrinking Sheet," Ain Shams Engineering Journal, 4(2), 259-264.

https://doi.org/10.1016/j.asej.2012.07.002

Dorier, C., and Tichy, J., 1992, "Behavior of a Bingham-Like Viscous Fluid in Lubrication Flows," Journal of Non-Newtonian Fluid Mechanics, 45(3), 291-310.

https://doi.org/10.1016/0377-0257(92)80065-6

Elbashbeshy, E.M.A., 2001, "Heat Transfer over an Exponentially Stretching Continuous Surface with Suction," Archives of Mechanics, 53(6), 643-651.

Fang, T., and Zhang, J., 2009, "Closed-form Exact Solution of MHD Viscous Flow over a Shrinking Sheet," Communications in Nonlinear Science and Numerical Simulation, 14(7), 2853-2857.

https://doi.org/10.1016/j.cnsns.2008.10.005

Ghosh, S., and Mukhopadhyay, S., 2017, "Viscous Flow Due to an Exponentially Shrinking Permeable Sheet in Nanofluid in Presence of Slip," International Journal for Computational Methods in Engineering Science and Mechanics, 18(6), 309-317. https://doi.org/10.1080/15502287.2017.1366598

Hayat, T., Abbas, Z., and Ali, N., 2008, "MHD Flow and Mass Transfer of a Upper-Convected Maxwell Fluid Past a Porous Shrinking Sheet with Chemical Reaction Species," Physics Letters A, 372(26), 46984704.

https://doi.org/10.1016/j.physleta.2008.05.006

Hayat, M., Shehzad, S.A., Alsaedi, A., 2012a, "Soret and Dufour Effects on Magnetohydrodynamic (MHD) Flow of Casson Fluid," Applied Mathematics and Mechanics, 33(10), 1301-1312.

Hayat, T., Iqbal, Z., Qasim, M., Obaidat, S., 2012b, "Steady Flow of an Eyring Powell Fluid over a Moving Surface with Convective Boundary
Conditions," International Journal of Heat and Mass Transfer, 55(7-8), 1817-1822.

https://doi.org/10.1016/j.ijheatmasstransfer.2011.10.046

Ishak, A., 2011, "MHD Boundary Layer Flow Due to an Exponentially Stretching Sheet with Radiation Effect," Sains Malaysiana, 40(4), 391395.

Jalil, M., Asghar, S., and Imran, S.M., 2013, "Self Similar Solutions for the Flow and Heat Transfer Powell-Eyring Fluid over a Moving Surface in a Parallel Free Stream," International Journal of Heat and Mass Transfer, 65, 73-79.

https://doi.org/10.1016/j.ijheatmasstransfer.2013.05.049

Lok, Y.Y., Ishak, A., Pop, I., 2011, "MHD Stagnation-Point Flow Towards a Shrinking Sheet," International Journal of Numerical Methods for Heat \& Fluid Flow, 21(1), 61-72. https://doi.org/10.1108/09615531111095076

Magyari, E., and Keller, B., 1999, "Heat and Mass Transfer in the Boundary Layers on an Exponentially Stretching Continuous Surface," Journal of Physics D: Applied Physics, 32(5), 577-585.

Mahapatra, T.R., and Gupta, A.S., 2001, "Magnetohydrodynamic Stagnation Point Flow Towards a Stretching Sheet," Acta Mechanica, 152(1-4), 191-196.

Miklavčič, M., and Wang, C.Y., 2006, "Viscous Flow Due a Shrinking Sheet," Quarterly of Applied Mathematics, 64, 283-290.

https://doi.org/10.1090/S0033-569X-06-01002-5

Moreau, R., 1990, Magnetohydrodynamics, Kluwer Academic Publishers, Dordrecht.

Mukhopadhyay, S., Layek, G.C., and Gorla, R.S.R., 2010, "Radiation Effects on MHD Combined Convective Flow and Heat Transfer Past a Porous Stretching Surface," International Journal of Fluid Mechanics Research, 37(6), 567-581.

Mukhopadyay, S., 2013, "Slip Effects on MHD Boundary Layer Flow over an Exponentially Stretching Sheet with Suction/Blowing and Thermal Radiation," Ain Shams Engineering Journal, 4(3), 485-491. https://doi.org/10.1016/j.asej.2012.10.007

Mukhopadhyay, S., and Mandal, I.C., 2015, "Magnetohydrodynamic (MHD) Mixed Convection Slip Flow and Heat Transfer over a Vertical Porous Plate," Engineering Science and Technology, an International Journal, 18(1), 98-105.

https://doi.org/10.1016/j.jestch.2014.10.001

Panigrahi, S., Reza, M., and Mishra, A.K., 2014, "MHD Effect of Mixed Convection Boundary-Layer Flow of Powell-Eyring Fluid Past Nonlinear Stretching Surface," Applied Mathematics and Mechanics, 35(12), 1525-1540.

Postelnicu, A., and Pop, I., 2011, "Falkner-Skan Boundary Layer Flow of a Power-Law Fluid Past a Stretching Wedge," Applied Mathematics and Computation, 217(9), 4359-4368.

https://doi.org/10.1016/j.amc.2010.09.037

Rajagopal, K.R., 1980, "Viscometric Flows of Third Grade Fluids," Mechanics Research Communications, 7(1), 21-25. https://doi.org/10.1016/0093-6413(80)90020-8

Rajagopal, K.R., Na, T.Y., and Gupta, A.S., 1984, "Flow of a Viscoelastic Fluid over a Stretching Sheet," Rheologica Acta, 23(2), 213-215.

Ridha, A., 1996, "Three-Dimensional Mixed Convection Laminar Boundary-Layer Near a Plane of Symmetry," International Journal of Engineering Science, 34(6), 659-675.

https://doi.org/10.1016/0020-7225(95)00122-0 
Roşca, A.V., and Pop, I., 2014a, "Flow and Heat Transfer of PowellEyring Fluid over a Shrinking Surface in a Parallel Free Stream," International Journal of Heat and Mass Transfer, 71, 321-327.

https://doi.org/10.1016/j.ijheatmasstransfer.2013.12.020

Roşca, A.V., and Pop, I., 2014b, "Flow and Heat Transfer over a Vertical Permeable Stretching/Shrinking Sheet with a Second Order Slip," International Journal of Heat and Mass Transfer, 60, 355-364. https://doi.org/10.1016/j.ijheatmasstransfer.2012.12.028

Sajid, M., and Hayat, T., 2008, "Influence of Thermal Radiation on the Boundary Layer Flow due to an Exponentially Stretching Sheet," International Communications in Heat and Mass Transfer, 35(3), 347356.

https://doi.org/10.1016/j.icheatmasstransfer.2007.08.006
Tamim, H., Dinarvand, S., Hosseini, R., and Pop, I., 2014, "MHD Mixed Convection Stagnation-Point Flow of a Nanofluid over a Vertical Permeable Surface: a Comprehensive Report of Dual Solutions," Heat and Mass Transfer, 50(5), 639-650.

Weidman, P.D., Kubitschek, D.G., and Davis, A.M.J., 2006, "The Effect of Transpiration on Self-Similar Boundary Layer Flow over Moving Surfaces," International Journal of Engineering Science, 44(11-12), 730-737.

https://doi.org/10.1016/j.ijengsci.2006.04.005

Wilkinson, W.L., 1970, "The Drainage of a Maxwell Liquid Down a Vertical Plate," The Chemical Engineering Journal, 1(3), 255-257. https://doi.org/10.1016/0300-9467(70)80008-9 